\title{
Concentrations of glycosaminoglycans in synovial fluids and their relation with immunological and inflammatory mediators in rheumatoid arthritis
}

Department of Pathology, Bristol University

A Bensouyad

A P Hollander

B Dularay

A E Bedwell

$R$ A Cooper

C J Elson

Department of

Rheumatology, Bristol

University

C $\mathbb{W}$ Hutton

P A Dieppe

Correspondence to:

Dr C J Elson, Department of Pathology, Bristol University, Bristol BS8 ITD.

Accepted for publication 3 July 1989 A Bensouyad, A P Hollander, B Dularay, A E Bedwell, R A Cooper, C W Hutton,
P A Dieppe, C J Elson

\begin{abstract}
The dimethylmethylene blue assay showed higher concentrations of glycosaminoglycans in many synovial fluids from patients with rheumatoid arthritis (RA) than in autologous sera or sera or synovial fluids from normal subjects. These results were taken to suggest that the glycosaminoglycans in RA synovial fluid were abnormally raised and derived from cartilage. To discover what stimulated such glycosaminoglycan release in RA joints relations were sought between synovial fluid concentrations of glycosaminoglycans and immunological and inflammatory mediators. It was shown that RA synovial fluid glycosaminoglycan concentrations correlated with synovial fluid C3d concentrations but not with synovial fluid rheumatoid factor concentrations, polymorphonuclear leucocyte numbers, myeloperoxidase concentrations, or the ability of the synovial fluids to release free radicals from normal polymorphonuclear leucocytes. A correlation was found between synovial fluid C3d and interleukin 1 concentrations as judged by both lymphocyte activating factor activity and immunoassay, but no significant correlation was detected between interleukin 1 and glycosaminoglycan concentrations. It is suggested that in the rheumatoid joint locally produced cytokines, in addition to interleukin 1, together stimulate glycosaminoglycan release from cartilage and render it vulnerable to attack by other processes.
\end{abstract}

Several hypotheses have been advanced to explain the pathogenesis of inflammation and joint damage in rheumatoid arthritis (RA). For example, it has been suggested that immune complexes in synovial fluid activate complement thereby attracting polymorphonuclear leucocytes into the joint space. Phagocytosis of the complexes triggers the release of polymorphonuclear leucocyte lysosomal enzymes and free radicals into the joint space and these may cause joint damage. This scheme is supported by the finding of IgG aggregates, ${ }^{1}$ activated complement components, ${ }^{2}$ high numbers of polymorphonuclear leucocytes, polymorphonuclear leucocyte lysosomal enzymes, ${ }^{3}$ and products of free radical action in RA synovial fluids. ${ }^{4}$ Polymorphonuclear leucocyte derived enzymes have been detected in arthritic cartilage from experimental animals ${ }^{5}$ and free radicals have been shown to degrade cartilage matrix in vitro. ${ }^{6}$ Another hypothesis suggests that local release of cytokines occurs in the joint and these stimulate chonodrocytes and osteoclasts to break down cartilage and bone respectively. The original impetus for this theory came from the discovery by Fell and Jubb that a factor from synovial membrane promoted cartilage degradation. ${ }^{7}$ More recently, cytokines, such as interleukin 1 and tumour necrosis factor, were shown to stimulate chondrocytes to degrade cartilage matrix ${ }^{89}$ and to stimulate osteoclasts to resorb bone ${ }^{10} 11$ in vitro, and these cytokines have been detected in RA synovial fluids. A third hypothesis suggests that sensitised $T$ lymphocytes react with antigen(s) in the joint and liberate lymphokines. Some of these would directly ${ }^{12}$ or indirectly (by stimulating other cells to produce cytokines) stimulate chondrocytes and osteoclasts to break down cartilage and bone respectively. Other lymphokines may activate phagocytic cells enabling them to bind collagen and modify the local environment so that their extracellular enzymes can initiate collagen degradation. ${ }^{13}$ There is unequivocal experimental evidence from animal models that $T$ cell reactions with antigens on or in the joint initiate arthritis. ${ }^{14} 15$ In addition, $T$ lymphocytes are prominent in rheumatoid synovial membranes, ${ }^{16} 17$ and $T$ lymphocytes already activated in vivo have been identified in a number of laboratories, including our own. ${ }^{18}$

From the observations summarised above it is apparent that a number of immune and inflammatory reactions are taking place in the joints of patients with RA. It remains to be established which (if any) of these reactions, either alone or in concert, causes joint damage. Our study attempts to approach this problem. Firstly, as degrading cartilage releases glycosaminoglycans in vitro, concentrations of glycosaminoglycan in synovial fluids were measured. Next, the concentrations of a number of putatively destructive immunological and inflammatory mediators were measured and correlations sought between their concentrations and glycosaminoglycan concentrations.

\section{Patients and methods}

PATIENTS

All patients (120 women, 56 men) fulfilled revised criteria for the diagnosis of RA. ${ }^{19}$ Their mean age was 60 (range 36-78) years and their mean disease duration 12 years. One hundred and fifty one $(86 \%)$ were seropositive by latex agglutination. They were being treated with a variety of analgesics, anti-inflammatory drugs, and slow acting antirheumatic drugs. Synovial fluids were obtained from the knee joint when 
arthrocentesis was indicated for therapeutic reasons. Samples were immediately mixed with citrate $(10 \% \mathrm{v} / \mathrm{v})$ and divided into two portions: the first was used to measure the total leucocyte count and the second was centrifuged within two hours of collection. A portion of the cell pellet was applied to a slide, air dried, and stained with Giemsa for differential leucocyte counts. The cell free supernate was stored in aliquots at $-70^{\circ} \mathrm{C}$, apart from $2-3 \mathrm{ml}$ which was mixed with ethylenediaminetetra-acetic acid (EDTA) before storage at $-70^{\circ} \mathrm{C}$. Serum samples were collected and separated from whole venous blood within one hour of arthrocentesis and stored in aliquots at $-70^{\circ} \mathrm{C}$. Samples of synovial fluid were also obtained from 28 patients with osteoarthritis, nine of whom had radiographic or synovial fluid evidence, or both, of crystal deposits. These samples were processed and stored in an identical way to the RA fluids.

Normal synovial fluid' samples were obtained from the knee joints of young volunteers without signs and symptoms of joint disease as described previously. ${ }^{20}$ Normal serum was obtained from other volunteers in the age range 30-70.

\section{GLYCOSAMINOGLYCAN ASSAY}

Estimation of sulphated glycosaminoglycan in synovial fluid and serum was carried out by the colorimetric method of Farndale et al, ${ }^{21}{ }^{22}$ with some modifications. Synovial fluid and serum samples were diluted to $10 \%(\mathrm{v} / \mathrm{v})$ and standard whale chondroitin sulphate (Sigma) was diluted to give a range of concentrations, using sodium phosphate buffer (50 mM, pH 7·0). Aliquots $(100 \mu \mathrm{l})$ of the samples and standards were transferred to polystyrene tubes (LP4, Luckham) and to each was added 0.13 units of papain (Sigma) in $100 \mu$ l of sodium phosphate buffer containing $2 \mathrm{mM} \mathrm{N}$-acetylcysteine (Sigma). The tubes were capped, vortex-mixed, and then incubated at $65^{\circ} \mathrm{C}$ for two hours. The papain was inactivated by addition of $50 \mu$ l of iodoacetic acid (Sigma; $20 \mathrm{mM}$ in $2.5 \mathrm{M} \mathrm{NaCl}$ ) to each tube. 1,9-Dimethylmethylene blue was prepared fresh for each experiment by dissolving $16 \mathrm{mg}$ of the dye (Serva, FRG), $3.04 \mathrm{~g}$ glycine (BDH), and $2.37 \mathrm{~g} \mathrm{NaCl}(\mathrm{BDH})$ in deionised water (final volume 1 litre). The $\mathrm{pH}$ was adjusted to 3.0 with concentrated hydrochloric acid. 1,9Dimethylmethylene blue $(2.5 \mathrm{ml})$ was added to each sample tube in turn and the absorbance at $525 \mathrm{~nm}$ read after 15 seconds against a dimethylmethylene blue/phosphate buffer blank. Preliminary experiments showed that a few synovial fluids may produce interference at $525 \mathrm{~nm}$ by absorbance which is independent of the dimethylmethylene blue. Therefore every synovial fluid sample was assayed in duplicate with 1,9-dimethylmethylene blue and also in duplicate with $2.5 \mathrm{ml}$ phosphate buffer alone (against a phosphate buffer blank), so that absorbance values could be corrected where necessary. Estimates of the concentration of glycosaminoglycan in each synovial fluid were made using the whale chondroitin sulphate standard curve.
ESTIMATION OF TOTAL C3d

C3d was measured by the double decker rocket immunoelectrophoresis method of Brandslund et $a l,{ }^{23}$ with some modifications. The samples were electrophoresed through two precipitating antibody gels; the first contained $40 \mu \mathrm{l} / \mathrm{ml}$ antiC3c (Dakopatts, Copenhagen), thus precipitating $\mathrm{C} 3$ and $\mathrm{C} 3 \mathrm{c}$ but allowing $\mathrm{C} 3 \mathrm{~d}$ to migrate into the second gel. This second gel contained antiC3d $(20 \mu \mathrm{l} / \mathrm{ml}$ of gel), but polyethylene glycol was not added. Polyclonal antihuman C3d was prepared at the South West Regional Blood Transfusion Centre. ${ }^{24}$ Volumes of synovial fluid ( $3 \mu \mathrm{l}$ ) and five dilutions of a standard serum (prepared from normal human serum incubated at room temperature for 10 days to allow the complete conversion of $\mathrm{C} 3$ to $\mathrm{C} 3 \mathrm{c}$ and $\mathrm{C} 3 \mathrm{~d}$ ) were applied to the gel. The results are expressed as a percentage of the amount of $\mathrm{C} 3 \mathrm{~d}$ in the standard serum.

\section{ESTIMATION OF IMMUNOGLOBULIN BOUND BY}

\section{ANTI-C3d}

This estimation was performed as described previously. ${ }^{25}$ Essentially, polyethylene glycol (2.5\%) precipitates of synovial fluids were incubated on the wells of plates which had been coated with monoclonal IgM antihuman $\mathrm{C} 3 \mathrm{~d} .{ }^{26}$ After washing, the amount of IgG attached to the plates was estimated by measuring the uptake of ${ }^{125} \mathrm{I}$ labelled monoclonal antihuman IgG. Counts obtained from control wells which had been blocked and incubated with antihuman IgG alone were subtracted from each sample count and the results expressed as a percentage of the total radioactivity bound to each well.

\section{RHEUMATOID FACTOR (RF) ASSAYS}

These radioimmunoassays were performed as described previously. ${ }^{27}$ Whole human IgG (for IgM RF assays) or human IgG1 Fc (for IgG RF assays) was used as antigen, and ${ }^{125} \mathrm{I}$ labelled monoclonal anti-IgM and anti-IgG $\left(\mathrm{CH}_{2}\right)$ were the indicators for detecting uptake of $\operatorname{IgM}$ and IgG respectively. Results were expressed as a percentage of the total labelled antibody bound by test samples.

\section{MYELOPEROXIDASE ASSAY}

Synovial fluid digested with bovine hyaluronidase (100 U/ml; Sigma) was assayed for myeloperoxidase by an adaptation of the method of Suzuki. ${ }^{28}$ The enzyme activity was measured spectrophotometrically using the substrate tetramethylbenzidine in the presence of hydrogen peroxide and the results expressed as the change in absorbance at $655 \mathrm{~nm} / 5 \mathrm{~min}$.

\section{STIMULATION OF POLYMORPHONUCLEAR}

LEUCOCYTE FREE RADICAL RELEASE BY SYNOVIAL FLUID

Superoxide generation was measured by superoxide dismutase inhibitable reduction of cytochrome $c$ using a recording double beam spectrophotometer. ${ }^{29}$ The sample and 
reference cuvette contained $10^{6}$ polymorphonuclear leucocytes and $1 \cdot 2 \mathrm{mg}$ cytochrome $c$ (horse heart type III; Sigma) in $1 \mathrm{ml}$ of Hanks's balanced salt solution (Gibco). The reference cuvette, in addition, contained $500 \mu \mathrm{g}$ superoxide dismutase (bovine erythrocytes; Sigma). The cells were stimulated with a range (2.5$20 \%$ ) of concentrations of RA synovial fluids, which were centrifuged at $1200 \mathrm{~g}$ for two minutes before use. The reduction of cytochrome $c$ was followed at $550 \mathrm{~nm}$ for 10 minutes. The nanomoles superoxide generated were calculated using an extinction coefficient of $21 \cdot 1 \mathrm{mM} / \mathrm{cm}$

\section{LYMPHOCYTE ACTIVATING FACTOR ACTIVITY}

This was performed as described by Gery et $a l,{ }^{31}$ with some modifications. Triplicate cultures were prepared in 96-well microtitre plates (Nunc); each well contained $2.5 \times 10^{5}$ mouse thymocytes in $200 \mu \mathrm{l}$ of RPMI 1640 medium containing $4 \mu \mathrm{g} / \mathrm{ml}$ phytohaemagglutinin (Wellcome) and $10 \%$ dilutions of hyaluronidase treated synovial fluid. Control wells contained thymocytes alone or thymocytes and phytohaemagglutinin. As a positive control, thymocytes were cultured in medium containing $10 \mathrm{ng} / \mathrm{ml}$ recombinant interleukin 1 (Roussel, UCLAF). After incubation for 48 hours at $37^{\circ} \mathrm{C}$ the thymocytes were pulsed with $37 \mathrm{kBq} /$ well of $\left[{ }^{3} \mathrm{H}\right]$ thymidine (Amersham) for the last six hours and harvested with an automatic cell harvester. Thymidine uptake was measured in a liquid scintillation counter. Data were expressed as the mean (SD) of triplicate cultures.

\section{IMMUNOASSAY FOR INTERLEUKIN $1 \beta$}

Hyaluronidase treated synovial fluids were assayed for interleukin $1 \beta$ by a monospecific enzyme linked immunosorbent assay (ELISA; Cistron Biotechnology/Laboratory Impex) according to the manufacturer's instructions.

\section{Results}

MEASUREMENT OF GLYCOSAMINOGLYCAN CONCENTRATIONS IN SYNOVIAL FLUID

Preliminary experiments were carried out to determine if RA synovial fluid contained inhibitors which would affect the detection of glycosaminoglycans. Accordingly, standard concentrations of chondroitin sulphate were prepared in the presence and absence of $10 \% \mathrm{RA}$ synovial fluid and the absorbance at $525 \mathrm{~nm}$ measured

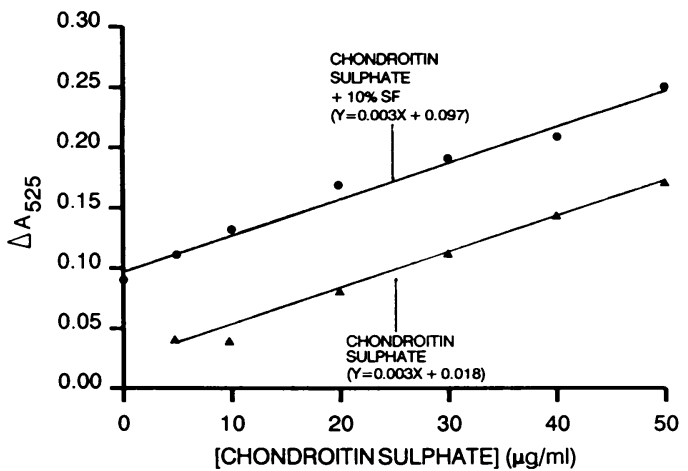

Effect of synovial fluid dilution on estimation of glycosaminoglycan concentrations*

\begin{tabular}{lllllll}
\hline $\begin{array}{l}\text { Synovial } \\
\text { fluid }\end{array}$ & \multicolumn{2}{l}{ Dilution } & & & & Mean (SD) \\
\cline { 2 - 6 } & $1 / 80$ & $1 / 40$ & $1 / 20$ & $1 / 10$ & $1 / 5$ & \\
\hline 1 & 130 & 140 & 140 & 130 & 130 & $134(5 \cdot 6)$ \\
2 & 120 & 140 & 130 & 118 & 138 & $129(10)$ \\
3 & 120 & 120 & 140 & 160 & 130 & $134(13)$ \\
4 & 100 & 100 & 85 & 75 & 100 & $92(11)$ \\
5 & 240 & 270 & 260 & 270 & NT & $260(14)$ \\
\hline
\end{tabular}

${ }^{*} \mu \mathrm{g} / \mathrm{ml}$ whole synovial fluid.

after addition of 1,9-dimethylmethylene blue. Figure 1 shows that the standard curve over the dose range used was linear, and synovial fluid did not alter the slope of the curve. Similar results were obtained with three other synovial fluids. In other experiments synovial fluids at different dilutions were assayed for glycosaminoglycan concentrations. The table shows that virtually the same values were obtained for the glycosaminoglycan concentration $/ \mathrm{ml}$ of whole synovial fluid over the range of dilutions tested.

The glycosaminoglycan concentrations in synovial fluids and serum samples from normal individuals and patients with RA and other arthritides were measured and the results are expressed in fig 2 . The mean glycosaminoglycan concentration in normal synovial fluid was 56 (range $10-150) \mu \mathrm{g} / \mathrm{ml}$, in normal sera was 85 (range $70-100) \mu \mathrm{g} / \mathrm{ml}$, and in RA sera was 84 (range $50-125$ ) $\mu \mathrm{g} / \mathrm{ml}$. By contrast, many of the values obtained for glycosaminoglycan concentrations in RA synovial fluids (mean 158, range $20-490 \mu \mathrm{g} / \mathrm{ml}$ ) and osteoarthritis synovial fluids

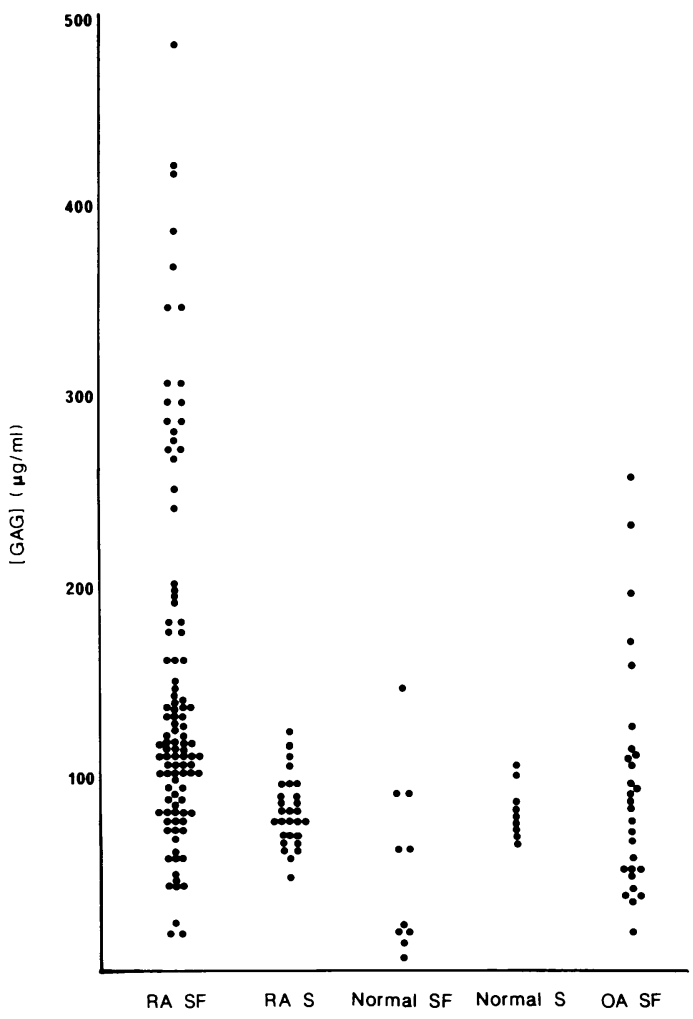

Figure 2: Comparison of glycosaminoglycan $(G A G)$ concentrations in rheumatoid arthritis $(R A)$ synovial fluid with those in sera from patients with $R A$ and normal individuals and synovial fluid from patients with other arthritides and normal individuals. $O A=$ osteoarthritis; $S F=$ synovial fluid; $S=$ sera . 
(mean 96, range $20-260 \mu \mathrm{g} / \mathrm{ml}$ ) were markedly raised. To determine whether glycosaminoglycan concentrations were consistently higher in individual RA synovial fluids than autologous sera the glycosaminoglycan concentrations in paired serum samples and synovial fluids from patients with RA were measured and the results are shown in fig 3.

CORRELATIONS BETWEEN IMMUNOLOGICAL AND INFLAMMATORY MARKERS AND GLYCOSAMINOGLYCAN CONCENTRATIONS

As raised RF concentrations are the most consistent abnormality in RA sera and synovial fluids IgM RF concentrations in RA synovial fluid were measured and relations sought between their level and glycosaminoglycan concentrations. Figure 4 shows that no correlation $(\mathrm{n}=37, \mathrm{r}=0.34$, NS) existed between glycosaminoglycan and IgM RF concentrations. Similar results were obtained for IgG RF levels and glycosaminoglycan concentrations $(n=37$, $r=0 \cdot 24$, NS).

The possible influence of complement activation and of the complexes which trigger activation was examined. Figure 5 shows the correlation ( $n=34, r=0.62, p<0.01)$ between glycosaminoglycan and $\mathrm{C} 3 \mathrm{~d}$ concentrations, which was confirmed with a second series of RA

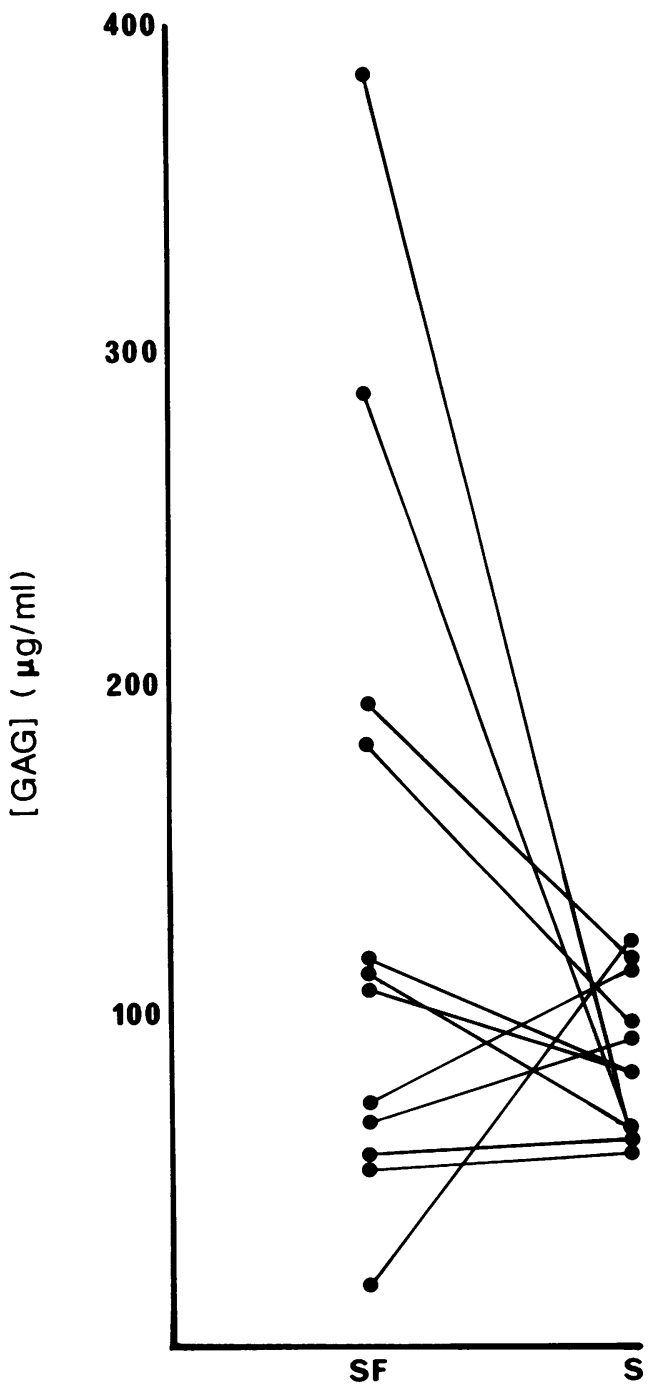

SF

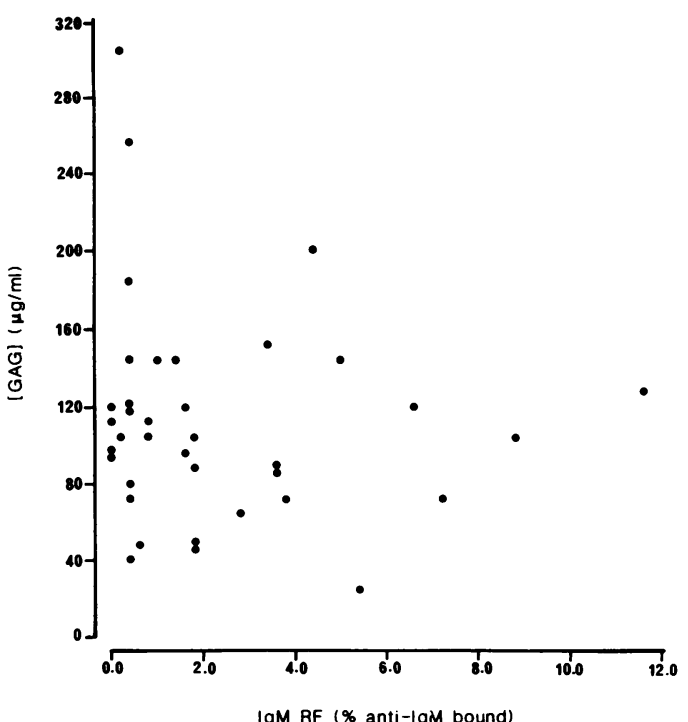

Figure 4: Relation between IgM rheumatoid factor (RF) and glycosaminoglycan (GAG) concentrations in rheumatoid arthritis synovial fluid.

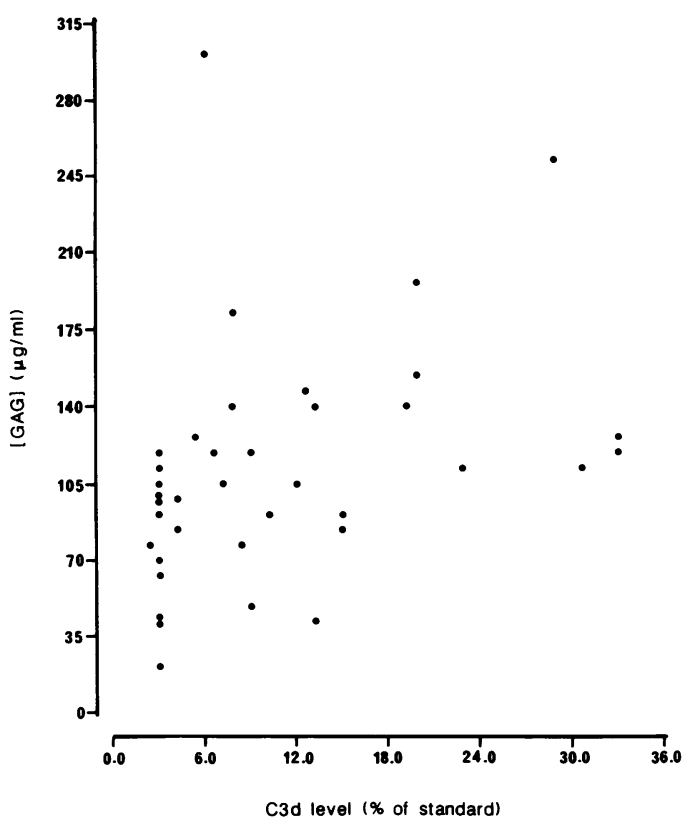

Figure 5: Relation between C3d levels and glycosaminoglycan (GAG) concentrations in rheumatoid arthritis synovial fluid.

synovial fluids ( $n=14, r=0.70, p<0.01)$. A comparison between the concentrations of IgG aggregates bearing $\mathrm{C} 3 \mathrm{~d}$ and glycosaminoglycan concentrations showed no correlation $(n=52$, $\mathrm{r}=0 \cdot 27, \mathrm{NS})$, however.

If polymorphonuclear leucocytes contribute to cartilage degradation in the joint then a relation might be expected between either polymorphonuclear leucocyte numbers or their products and glycosaminoglycan concentrations. We found no correlation between glycosaminoglycan concentrations and synovial fluid polymorphonuclear leucocyte numbers $(n=56$, $r=0 \cdot 12$, NS), however. Similarly, there was no correlation between synovial fluid myeloperoxidase concentrations and glycosaminoglycan concentrations $(n=51, r=0.24$, NS). The ability of RA synovial fluids to stimulate the release of
Figure 3: Comparison of glycosaminoglycan (GAG) concentrations in rheumatoid arthritis synovial fluids (SFs) and autologus serum samples $(S)$. 


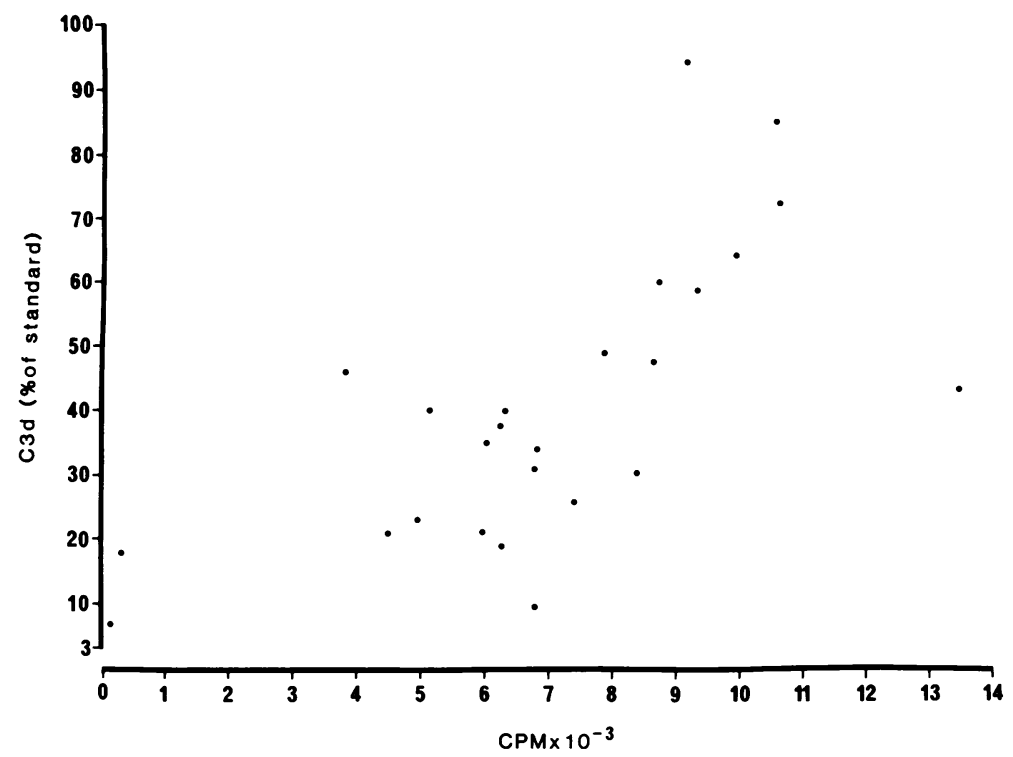

Figure 6: Relation between lymphocyte activating factor activity and glycosaminoglycan concentrations in rheumatoid arthritis synovial fluid.

free radicals from normal polymorphonuclear leucocytes was measured but only $7 / 47$ were active, and thus this variable too was unrelated to glycosaminoglycan concentrations.

Complement activating immunoglobulin aggregates but not immunoglobulin aggregates alone ${ }^{32}$ have been shown to stimulate the release of interleukin 1-a known stimulant of cartilage degradation-from monocytes. These findings prompted us to ask, firstly, if there is a relation between complement activation in RA synovial fluid and synovial fluid interleukin 1 concentrations, and, secondly, if the relation (reported above) between $\mathrm{C} 3 \mathrm{~d}$ concentrations and glycosaminoglycan concentrations might be due to complement activation stimulating local interleukin 1 production, which in turn stimulates glycosaminoglycan release from cartilage. Figure 6 shows that the levels of synovial fluid lymphocyte activating factor activity and $\mathrm{C} 3 \mathrm{~d}$ were related $(n=25, r=0.68, p<0.01)$. In addition, synovial fluid interleukin $1 \beta$ concentrations, as judged by an ELISA, correlated with C3d concentrations $(n=9, r=0.61, p<0.05)$. Finally, a possible relation between synovial fluid glycosaminoglycan concentrations and interleukin 1 concentrations was sought. No significant relation ( $n=20, r=0.42$, NS) between immunoreactive interleukin $1 \beta$ concentrations and glycosaminoglycan was found and no relation $(n=20, r=0 \cdot 29, N S)$ between lymphocyte activating factor activity and glycosaminoglycan concentrations.

\section{Discussion}

Dingle and his colleagues ${ }^{33}$ and Carroll $^{34}$ were the first to report the detection of glycosaminoglycans by the dimethylmethylene blue assay in arthritic synovial fluids. Our results extend their work by showing that many RA synovial fluids have high glycosaminoglycan concentrations as compared with serum samples or synovial fluids from normal individuals. The synovial fluids from normal joints were obtained from young healthy volunteers who were not matched for age and sex with the patient groups. Most had glycosaminoglycan concentrations which were similar to normal serum concentrations, in contrast with the raised synovial fluid, but not serum concentrations, found in RA. Although age of subjects and sample stage could be compounding variables, it seems likely that the high glycosaminoglycan concentrations found in many pathological synovial fluids represent a true variation in cartilage derived products.

These observations raise the question of how pathological synovial fluid glycosaminoglycan concentrations relate to cartilage degradation in vivo. Normal cartilage consists mainly of collagen and proteoglycans; the latter being complex macromolecules consisting of an extended protein core to which are attached glycosaminoglycan side chains. In normal cartilage proteoglycans turn over slowly and as the degraded molecules are released they are replaced by newly synthesised components. ${ }^{35}$ Animal experiments have shown that intra-articular injection of agents, which either inhibit the synthetic capacity of chondrocytes or their production of degradative enzymes, cause a net loss of cartilage and also increased glycosaminoglycan concentrations in synovial fluid, at least in the short term. ${ }^{36}{ }^{37}$ In view of these findings and because higher concentrations of glycosaminoglycan were found in many RA synovial fluids than in autologous serum samples and normal synovial fluids it seems reasonable to assume that the glycosaminoglycans found in RA synovial fluid derive from cartilage. Whether the high concentrations found in RA synovial fluid result from increased synthesis and release of RA cartilage glycosaminoglycan or from increased degradation of cartilage matrix glycosaminoglycan remains unclear, though degradation seems the most likely. A third possibility-namely, that the process which leads to removal of glycosaminoglycan from the joint space is inhibited in patients with RA, is not supported by animal experiments, which showed that the clearance rate of glycosaminoglycan from normal and arthritic synovial fluids was similar (half lives of 12 hours and 14 hours respectively). ${ }^{38}$

As already mentioned (see 'Introduction') a number of processes take place in RA joints which might affect the cartilage. It was hoped to elucidate which (if any) of these processes is important in relation to cartilage degradation by asking if particular initiators or mediators of immunological and inflammatory joint reactions were related to synovial fluid glycosaminoglycan concentrations. The results showed that no correlation exists between glycosaminoglycan concentrations and polymorphonuclear leucocyte numbers or between glycosaminoglycan concentrations and those of synovial fluid myeloperoxidase. Moreover, most RA synovial fluids were unable to stimulate the release of free radicals from normal polymorphonuclear leucocytes. It is thus tempting to speculate that polymorphonuclear leucocyte degranulation and release of free radicals is not important in causing cartilage damage. No significant correlation was found between RA synovial fluid 
concentrations of glycosaminoglycan and interleukin 1, however, despite the known ability of this cytokine to stimulate glycosaminoglycan release from animal cartilage. One explanation for these results is that the patients have reached different stages of the disease and different processes may be involved at these different stages. Therefore, non-corrrelation of glycosaminoglycan concentrations with particular indices may not be evidence for non-causal relations. Alternatively, the power of association between each variable may be too small for a statistically significant relation between interleukin 1 and glycosaminoglycan concentrations to emerge from the small number of patients assayed. Finally, cytokines in addition to interleukin 1 may stimulate glycosaminoglycan release from RA cartilage in vivo. It may be significant that recent work from our laboratories (Hollander, Atkins, Dieppe, and Elson, unpublished) has shown that RA synovial fluids do stimulate glycosaminoglycan release from live human cartilage in vitro, though interleukin 1 at concentrations 20 times those found in the fluid is without effect.

A correlation was found between C3d and glycosaminoglycan concentrations. This result might be due to glycosaminoglycan activating complement either directly or indirectly by reacting with an autoantibody, but to our knowledge there is no evidence for these hypotheses. We also considered the possibility that complement activation is related to the local production of interleukin 1 as it is known that interleukin 1 production may be stimulated by complement activating IgG aggregates ${ }^{32}$ and by the binding of $\mathrm{C} 5$ a to macrophages. ${ }^{39}$ In support of this contention synovial fluid lymphocyte activating factor activity and C3d concentrations were found to be related. It might be argued that the synovial fluid lymphocyte activating factor activity was due to the presence of a cytokine such as interleukin 6 rather than interleukin 1 but a correlation, albeit weaker, was found between interleukin 1 concentrations, as judged by immunoassay, and C3d concentrations in a small group of fluids. Despite these results the explanation for the relation between synovial fluid glycosaminoglycan and C3d concentrations remains uncertain.

In conclusion, it has been shown that some RA synovial fluids contain increased concentrations of glycosaminoglycans, which are thought to be released from cartilage. The results failed to support a role for polymorphonuclear leucocyte derived degradative enzymes or free radicals in glycosaminoglycan release. Similarly, no evidence was found for the involvement of interleukin 1, and it is suggested that glycosaminoglycan release is stimulated by a mixture of cytokines. How glycosaminoglycan loss from cartilage is involved in the rheumatoid process remains to be established, but we postulate that the loss occurs over much of the cartilage thereby rendering cartilage more susceptible to attack at the pannus-cartilage junction.

This work was supported by grants from the Medical Research Council and the Arthritis and Rheumatism Council. Mr A BenSouyad was supported by a grant from the Algerian Ministry for Higher Education (MES). We thank Dr A Abdel-Nour for his help with the lymphocyte activating factor assay, Dr J Kirwan for supplying synovial fluid and helpful discussion, and Dr J Lowe (Department of Immunology, University of Birmingham) for his gift of ${ }^{125}$ I labelled monoclonal antihuman IgG.

1 Winchester R J, Agnello V, Kunkel H G. Gamma globulin complexes in synovial fluid of patients with rheumatoid arthritis. Partial characterization and relationship to lowered complement levels. Clin Exp Immunol 1970; 6: 689-706.

2 Zvaifler N J. Breakdown products of C3 in human synovial

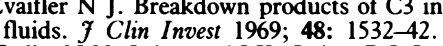

3 Hadler N M, Spitznagel J K, Quinet R J. Lysosomal enzymes in inflammatory synovial effusions. $\mathcal{J}$ Immunol 1979; 123: $572-7$.

4 Lunec H, Halloran P, White A G, Dormandy T L. Free radical oxidation (peroxidation) products in serum and synovial fluid in rheumatoid arthritis. $\mathcal{F}$ Rheumatol $1981 ; 8$ : $233-45$

5 Sandy J D, Sriratana A, Brown H L G, Lowther D A. Evidence for polymorphonuclear-leukocyte-derived proteinases in arthritic cartilage. Biochem f 1981; 193: 193-202.

6 Burkhardt J, Schwingel M, Menninger J, Macartney H W, Burkhardt J, Schwingel $M$, Menninger J, Macartney $H W$,
Txchesche $H$. Oxygen radicals as effectors of cartilage destruction. Direct degradative effect on matrix components and indirect action via activation of latent collagenase from polymorphonuclear leukocytes. Arthritis Rheum 1986; 29: 379-87.

7 Fell $H$ D, Jubb $R$ W. The effect of synovial tissue on the breakdown of articular cartilage in organ culture. Arthritis Rheum 1977; 20: 1359-72.

8 Saklatvala J, Pilsworth L M C, Sarsfield S J, Gavrilovic J, Heath J K. Pig catabolin is a form of interleukin 1. Cartilage and bone resorb fibroblasts make prostaglandin and collagenase, and thymocyte proliferation is augmented in lagenase, and thymocyte proliferation is augmented
response to one protein. Biochem $\mathcal{f} 1984 ; 224: 461-6$.

9 Saklatvala J. Tumour necrosis factor-stimulates resorption and inhibits synthesis of proteoglycan in cartilage. Nature 1986; 322: 547-9.

10 Rifas L, Shen V, Mitchell K, Peck W A. Macrophagederived growth factor for osteoblast-like cells and chondrocytes. Proc Natl Acad Sci USA 1984; 81: 4558-62.

11 Bertolini D R, Nedwin G E, Bringman T S, Smith D D, Mundy G R. Stimulation of bone resorption and inhibition of bone formation in vitro by human tumour necrosis factors. Nature 1986; 319: 516-8.

12 Horowitz M, Vignery A, Gershon R K, Baron R. Thymusderived lymphocytes and their interactions with macrophages are required for the production of osteoclast-activatphages are required for the production of osteoclast-activating factor

13 Pugh D, Etherington D J, Silver I A. Acid hydrolase distribution in sensitised and naive macrophages in vivo and in vitro. Z Mikrosk Anat Forsch 1984; 98: 375-84.

14 Brachertz D, Mitchell G F, Vadas M A, Mackay I R. Studies on antigen-induced arthritis in mice. III. Cell and serum transfer experiments. F Immunol 1977; 118: 1643-8.

15 van Eden W, Haloshitz J, Nevo Z, Frenkel A, Klajman A, Cohen I R. Arthritis induced by a T lymphocyte clone that responds to $M$. tuberculosis and to cartilage proteoglycans. Proc Natl Acad Sci USA 1985; 82: 5117-20.

16 Duke O, Panayi G S, Janossy G J, Poulter L W. An immunohistological analysis of lymphocyte subpopulations and their microenvironment in the synovial membrane of patients with rheumatoid arthritis using monoclonal antipatients with rheumatoid arthritis using mond
bodies. Clin Exp Immunol 1982; 49: 22-30.

17 Kurosaka M, Ziff M. Immunoelectron microscopic study of the distribution of T-cell subsets in rheumatoid synovium. $\mathcal{F}$ Exp Med 1983; 158: 1191-210.

18 Abdel-Nour A, Elson C J, Dieppe P A. Proliferative responses to T-cell lines grown from joint fluids of patients with rheumatoid arthritis. Immunol Lett 1986; 12: 329-33.

19 Arnett F C, Edworthy S M, Block D A, et al. The American Rheumatism Association revised criteria for the classification of rheumatoid arthritis. Arthritis Rheum 1988; 31: 315-24.

20 Fawthrop F, Hornby J, Hutton C W, Docherty M, Dieppe Fawthrop F, Hornby J, Hutton C W, Docherty M, Dieppe P A. A comparison of pathological and
fluids. Br $\mathcal{F}$ Rheumatol 1985; 24: 61-9.

21 Farndale R W, Sayers C A, Barrett A J. A direct spectrophotometric microassay for sulphated glycosaminoglycans in cartilage cultures. Connect Tissue Res 1982; 9: 247-8.

22 Farndale R W, Buttle D J, Barrett A J. Improved quantitation and discrimination of sulphated glycosaminoglycans by use of dimethyl methylene blue. Biochim Biophys Acta 1986; 883: 173-7.

23 Brandslund I, Siersted H C, Svehag S E, Teisner B. Double decker rocket immunoelectrophoresis for direct quantitation of complement $\mathrm{C} 3$ split products with C3d specificities in plasma. F Immunol Methods 1981; 44: 63-71.

24 Elson C J, Scott D G I, Blake D, Bacon P A, Hoult P G I. Complement activating rheumatoid factor containing complexes in patients with rheumatoid vasculitis. Ann Rheum Dis 1983 ; 42: 147-50.

25 Bedwell A E, Elson C J, Carter S D, Dieppe P A, Hutton C W, Czudek R. Isolation and analysis of complement C W, Czudek R. Isolation and analysis of complement activating aggregates from synovial fluid of patients with rheumatoid arthritis using monoclon

26 Holt P D J, Donaldson C, Judson P A, Johnson P, Parsons S F, Anstee D J. NBTS/BRIC8: a monoclonal anti-C3d antibody. Transfusion 1985; 26: 267-79.

27 Elson C J, Carter S D, Scott D G I, Bacon P A, Lowe J. A 
new IgG rheumatoid factor assay and its use to analyse rheumatoid factor reactivity with human IgG isotypes. Rhevomatol Int 1985; 5: 175-9.

28 Suzuki K, Ota H, Sasagawa S, Sakatani T, Fujikura T. Assay method for myeloperoxidase in human polymorphonuclear leukocytes. Anal Biochem 1982; 132: 345-52.

29 Babior B M, Kipnes S, Carnutte J T. Biological defence mechanism: the production by leukocytes of superoxide, a potential bactericidal agent. 7 Clin Irevest 1973; 52: 741-4.

30 Dularay B, Elson C J, Dieppe P A. Enhanced oxidative response of polymorphuclear leutocytes from synovia fluids of patients with rheumatoid arthritis. Autoimmonity 1988; 1: 159-69.

31 Gery I, Gershon R K, Walsman B H. Potentiation of T lymphocyte responses to mitogens. F Exp Med 1972; 136 : $128-42$.

32 Arend W P, Joslin F G, Massoni R J. Effects of immune complexes on production by human monocytes of interleukin-1 or an interleukin-1 inhibitor. F Immunol 1985; 134: 3868-75.

33 Dingle J T, Page Thomas D P, Hazleman B. The role of cytokines in arthritic diseases: in vitro and in vivo measurements of cartilage degradation. Int $\mathcal{f}$ Tissue React 1987; 9: 349-54.

34 Carroll G J. Spectrophotometric measurement of proteoglycans in osteoarthritic synovial fluid. Ann Rhewan Dis 1987; 46: 375-9.

35 Hardingham T E, Burditt L J, Ratcliffe A. Studies on synthesis, secretion and assembly of proteoglycan aggregates synthesis, secretion and assembly of proteoglycan aggregates

36 Pettipher E R, Higgs G A, Henderson B. Interleukin induces leukocyte infiltration and cartilage proteoglycan induces leukocyte infiltration and cartilage proteoglycan degradation in the

37 Dingle J T, Page Thomas D P, King B, Bard D R. In vivo studies of articular tissue damage mediated by catabolin interleukin 1. Ann Rhewm Dis 1987; 46: 527-33.

38 Page-Thomas D P, Bard D, King B, Dingle J T. Clearance of proteoglycan from joint cavities. Anm Rhewm Dis 1987; 46: 934-7.

39 Goodman M G, Chenoweth D E, Weigle W O. Induction of interleukin-1 secretion and enhancement of humoral immunity by binding of human $\mathrm{C5a}$ to macrophage $\mathrm{C} 5 \mathrm{a}$ receptors. F Exp Med 1982; 156: 912-7. 